Bangladesh J. Plant Taxon. 16(2): 165-174, 2009 (December)

(C) 2009 Bangladesh Association of Plant Taxonomists

\title{
POLLEN MORPHOLOGY OF 10 TAXA BELONGING TO PRANGOS LINDL. AND EKIMIA H. DUMAN \& M.F. WATSON (UMBELLIFERAE) FROM TURKEY AND ITS TAXONOMIC SIGNIFICANCE
}

\author{
Sevil Pehlivan $^{1}$, Birol Bașer ${ }^{2}$ and Evren $\mathrm{Cabi}^{3}$ \\ Department of Biology, Faculty of Science and Art, Gazi University, Ankara, Turkey. \\ Keywords: Ekimia; Pollen morphology; Prangos; SEM; Taxonomy; TEM.
}

\begin{abstract}
Pollen grains of nine taxa of Prangos Lindl. and one of Ekimia H. Duman \& M.F. Watson (Umbelliferae) were examined with LM (light microscope) and SEM (scanning electron microscope), and of them four with TEM (transmission electron microscope). The quantitative data were also subjected to cluster analysis. The obtained phenogram revealed that Ekimia bornmuelleri (Hub.-Mor. \& Reese) H. Duman \& M.F. Watson is strictly different from the taxa of Prangos regarding their quantitative pollen profile; except $P$. ferulacea Lindl., all taxa included in section Intactae formed a cluster together; members of section Meliocarpoides and section Prangos show a closer relationship regarding their pollen features. Exine ornamentations of Prangos and Ekimia are rugulatestriate and are of no value for identification purposes.
\end{abstract}

\section{Introduction}

The genus Prangos Lindl. has around 28 species worldwide (Herrnstadt and Heyn, 1972; 1977). The Anatolian part of Turkey is considered as one of the primary centers of the genus (Duran et al., 2005). In the Flora of Turkey, Herrnstadt and Heyn (1972) recognized 10 species of Prangos. In addition, they mentioned about two incompletely known species, namely Cachyrys papillaris Boiss. and P. bornmuelleri Hub.-Mor. \& Reese. Later on, Duman and Watson (1999) transferred P. bornmuelleri to the monotypic genus Ekimia H. Duman \& M.F. Watson as E. bornmuelleri (Hub.-Mor. \& Reese) H. Duman \& M.F. Watson. Since the publication of the Flora of Turkey, three more species of Prangos were described from Turkey, making the total species number 13 (Davis et al., 1988; Duman and Watson, 1999; Duman, 2000; Duran et al., 2005).

There are plenty of studies concerning the pollen morphological features of the family Umbelliferae (Erdtman, 1952; Cerceau-Larrival, 1962, 1963, 1965; Aytuğ et al., 1971; Cerceau-Larrival, 1971; Ferreira and Purper, 1972; Cerceau-Larrival and Roland Heydacker, 1976; Herrnstadt and Heyn, 1977; Moore and Webb, 1978; Punt, 1984). Pollen grains of Umbelliferae are usually very distinctive with their inner and outer outlines and very characteristic 'bone' shape. These distinctive palynological features have also been used by several authors in general pollen keys (Erdtman, 1952; Aytuğ et al., 1971; Moore and Webb, 1978).

\footnotetext{
1 E-mail: pehlivan@gazi.edu.tr

2 E-mail: baser@gazi.edu.tr

${ }^{3}$ Corresponding author. Department of Biological Sciences, Faculty of Arts and Sciences, Middle East Technical University, Ankara, Turkey. E-mail: ecabi2004@yahoo.com; ecabi@metu.edu.tr
} 
The previous study on pollen morphology of Prangos was limited and conducted using only light microscope (Herrnstadt and Heyn, 1977). Therefore, an attempt has been made to describe the palynological features of the genera Prangos (nine taxa) and Ekimia (one species) to validate the utility of these data to provide additional support to sectional groups currently recognized within Prangos and also to provide new insights on the justification of transfer of $P$. bornmuelleri to Ekimia using numerical approach.

\section{Materials and Methods}

The pollen characteristics of nine Prangos taxa belonging to three sections, namely sect. Meliocarpoides, sect. Prangos and sect. Intactae, and one taxon of Ekimia were studied (Table 1). Seven of these taxa are endemic to Turkey. The studied plant materials were collected from different populations in Turkey. A list of specimens examined is given in Table 1.

Table 1. Voucher specimens of $\mathbf{1 0}$ taxa of Ekimia and Prangos.

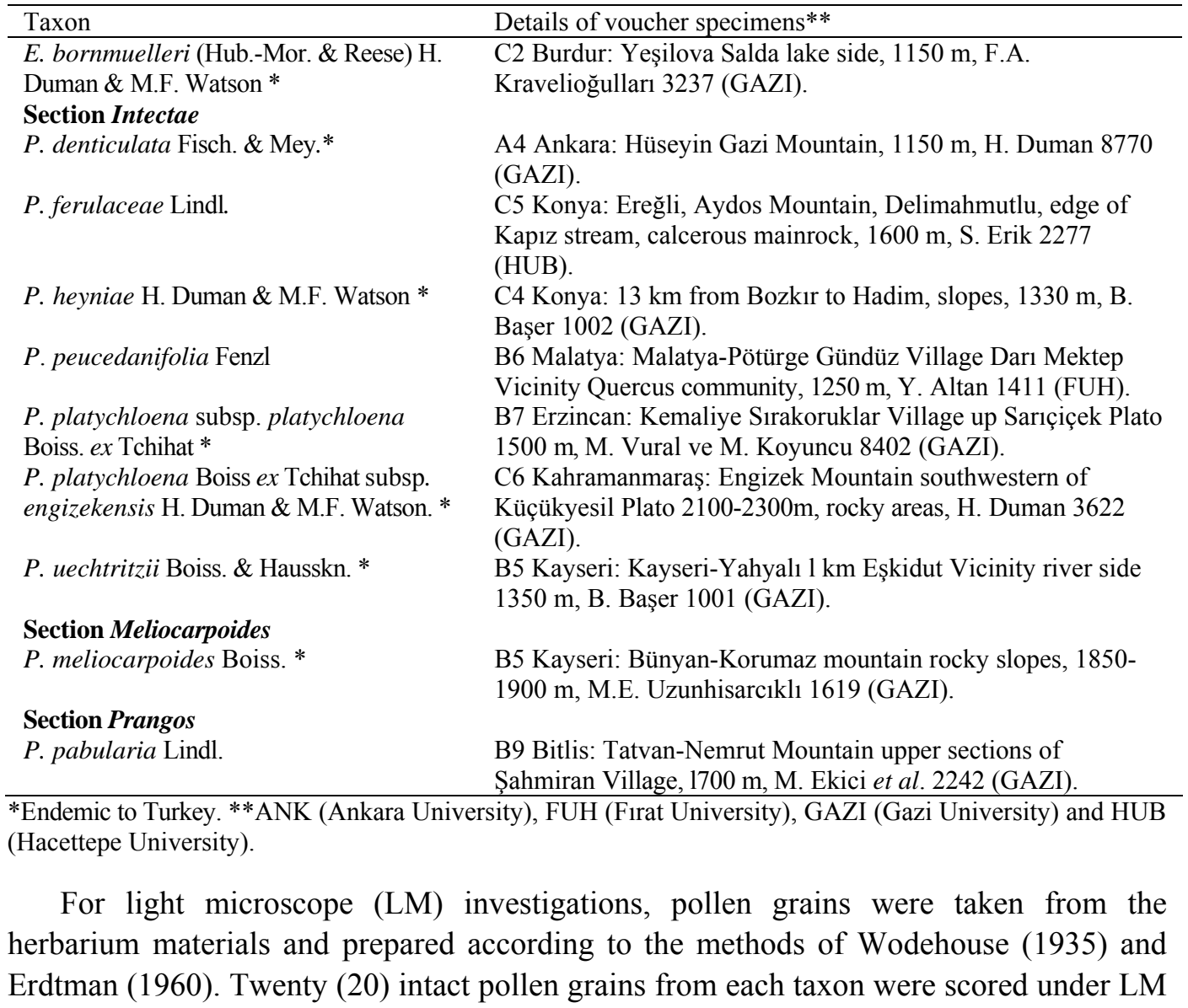


(Leica DM 1000) for the following parameters: P, polar axis; E, equatorial diameter; $\mathrm{P} / \mathrm{E}$, ratio of polar axis and equatorial diameter; $\mathrm{Clg}$, colpus length; Clt, colpus diameter; Plg, pore length; Plt, pore width; I, thickness of intine; Coswid, costae width.

Cluster analysis (CA) was performed to determine the pattern of grouping of the taxa based on these nine quantitative pollen characters. In CA, the data matrix were used to produce the distance matrix based on Gower General Similarity Coefficient by the group average method as suggested by Gower (1971) using statistic package MVSP version 3.1 (Kovach, 1999).

For scanning electron microscope (SEM) investigations, the pollen grains were put on stubs, sputter-coated with gold plate, and examined under a Jeol JSM-6060 scanning electron microscope. For transmission electron microscope (TEM) studies, acetolysed pollen grains were stained with $2 \% \mathrm{OsO}_{4}$ and with uranil acetate, dehydrated and embedded in epon-araldite (Skvarla and Turner, 1966). Ultrathin sections of the pollen grains were obtained with a glass knife in a Reichert Supernova microtome. Post-staining was done with lead citrate for 5 minutes (Reynold, 1963), and the sections were examined under a Jeol 1220 TEM. The terminologies for pollen morphology proposed by Punt (1984) and Faegri and Iversen (1989) were followed.

\section{Results and Discussion}

According to LM and SEM investigations, the pollen grains of the taxa belonging to Prangos and Ekimia, are perprolate, trizonocolporate, operculate, isopolar and bilaterally symmetrical, subrectangular in equatorial view, triangular in polar view (Figs 1-10), with a rugulate-striate exine sculpture (Figs 11-20). There is a thickening around the aperture of exine (costae) with a decreasing diameter towards the poles. Apertures are on the same plane in the equatorial region (Figs 1-10).

Pollen grains of the Umbelliferae show uniformity to some extent. Detailed palynogical investigations have been carried out by Cerceau-Larrival (e.g. 1962, 1963, 1965, 1971). As a result of these investigations, five basic types, namely subrhomboidal $(\mathrm{Rh})$, subcircular $(\mathrm{C})$, ovoid $(\mathrm{O})$, subrectangular $(\mathrm{Rg})$ and equatorially constricted $(\mathrm{E})$, were defined according to inner outline of the endexine (nexine). Two species were examined from the genus Prangos "Cachrys alpina" (= Prangos trifida (Miller) I. Herrnstadt \& Heyn) and "Cachrys goniocarpa" (= P. ferulacea). On the basis of CerceauLarrival's classification, all studied pollen grains of the present study were consistent with subrectangular pollen type.

Herrnstadt and Heyn (1977) studied acetolyzed pollen of eight species of Prangos and six of them are included in our study. They found the range of pollen grains from 39 to $65 \mu \mathrm{m}$ in size. In our study, we found that E. bornmuelleri $(29.24 \pm 1.17$ (A)) has the shortest pollen grains relative to the taxa of Prangos $(32.49 \pm 2.32-48.23 \pm 2.59$ (A)) (Table 2). 
SEM investigations revealed that all investigated taxa have rugulate-striate ornamentation. Punt (1984) stated that ornamentation is of little value as a discriminating factor for identification of pollen grains in Umbelliferae. Three ornamentation patterns have been determined in his studies: irregularly regulate, irregularly striate or cerebroid. Punt, however, did not examine any species belonging to the genus Prangos. Aytuğ et al. (1971) also studied the pollen grains of species of Ferula (Tourn.) L. and Oenante (Tourn.) L. belonging to Umbelliferae. He noted that these pollen grains have exine sculptures in the form of simple columella.

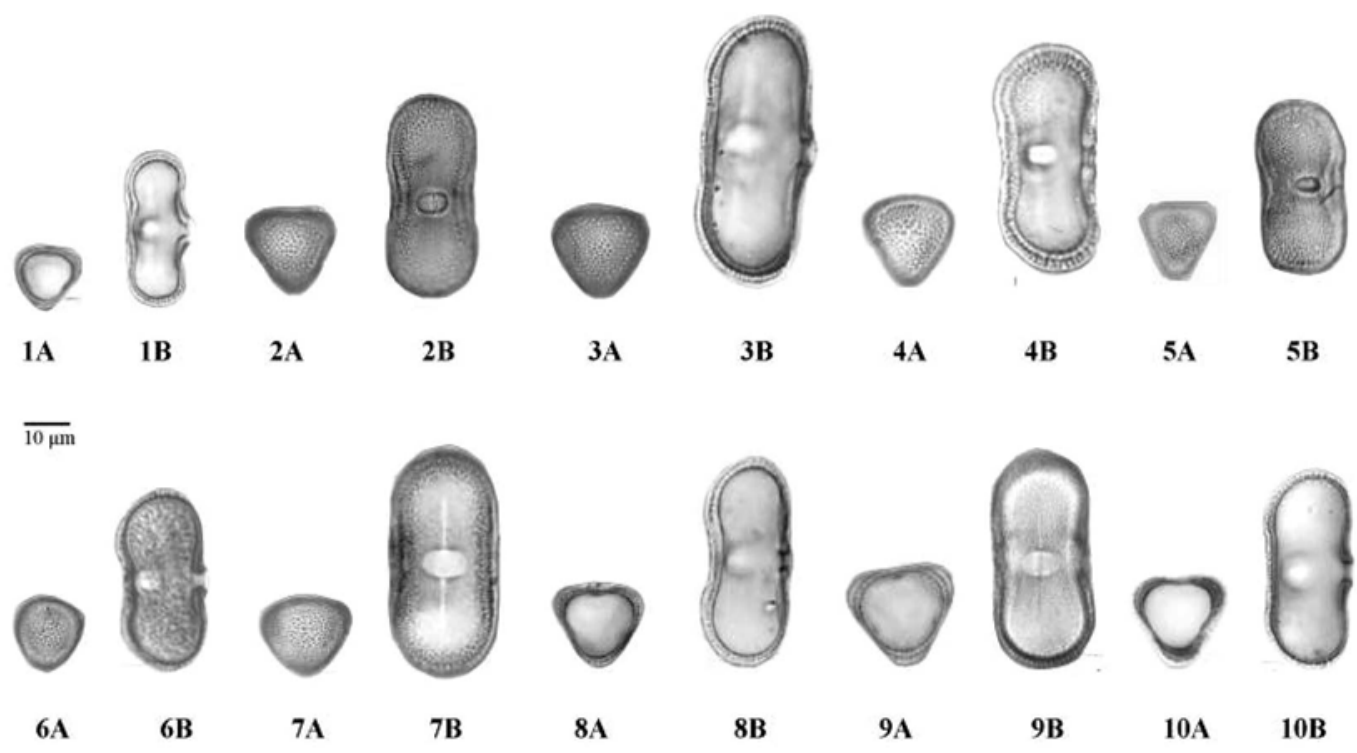

Figs 1-10. Light photomicrographs of acetolyzed pollen grains of Ekimia and Prangos taxa. A, polar view; B, equatorial view. 1. E. bornmuelleri; 2. P. denticulata; 3. P. ferulacea; 4. P. heyniae; 5. P. meliocarpoides; 6. P. pabularia; 7. P. peucedanifolia; 8. P. platychloena subsp. platychloena; 9. P. platychloena subsp. engizekensis; 10. P. uechtrizii.

The present TEM examinations revealed that endexine is very thin in all studied taxa. Endexine is thinner in Ekimia pollen grain in comparison with Prangos pollen grains. Ectexine is observed to be thinnest in P. meliocarpoides (Table 3, Fig. 21).

The results of the present study indicate that the most variable pollen characteristics among the investigated taxa are the polar axis, equatorial axis and colpus length. The relative size of pollen grains was determined to be effective in separating the genera Ekimia and Prangos. The polar and equatorial axes are smaller in Ekimia than the members of Prangos. The genus Prangos, especially section Intactae shows variability regarding their pollen sizes. Section Meliocarpoides and section Prangos have similar pollen characteristics thus formed a tight cluster on the obtained phenogram (Table 2, Fig. 22). 


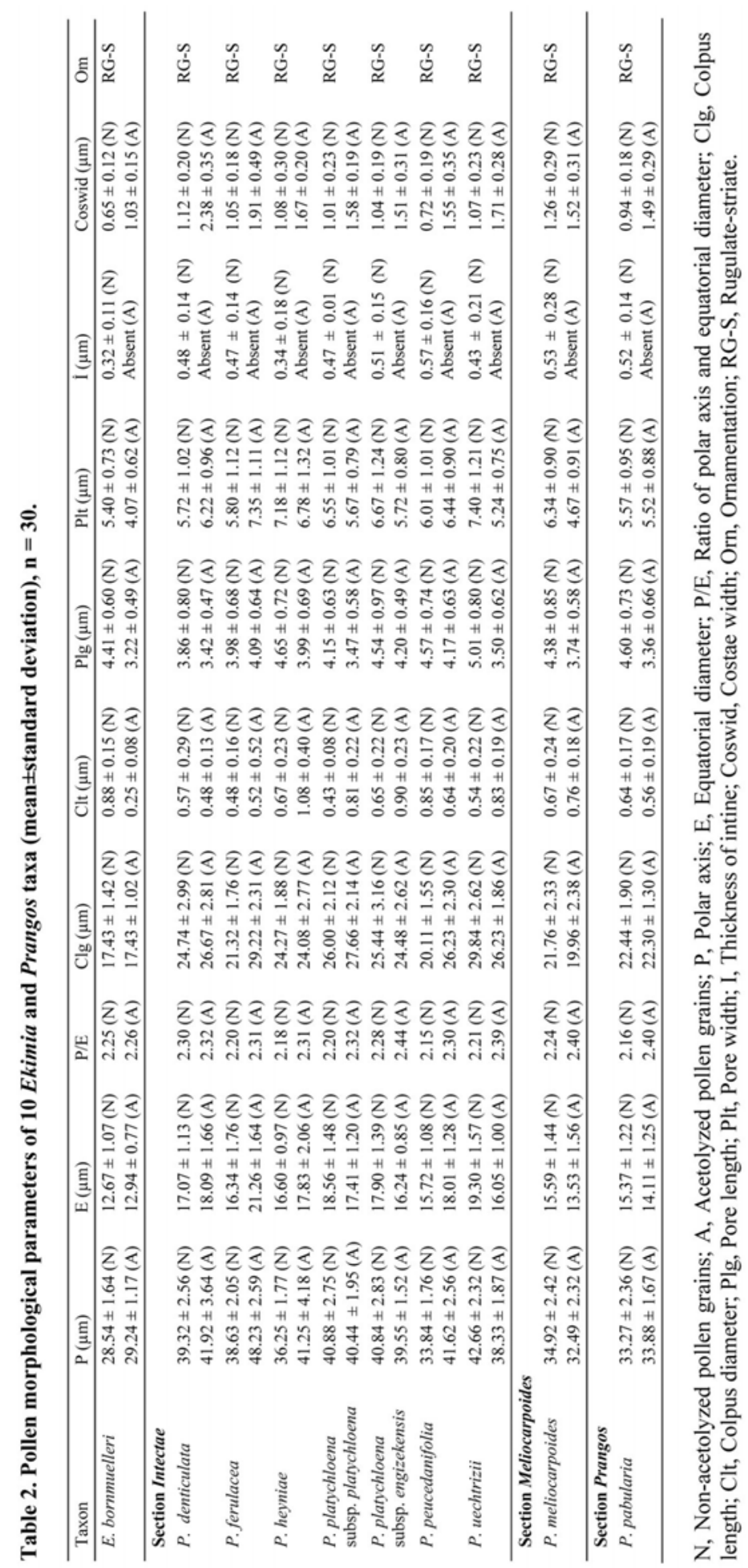



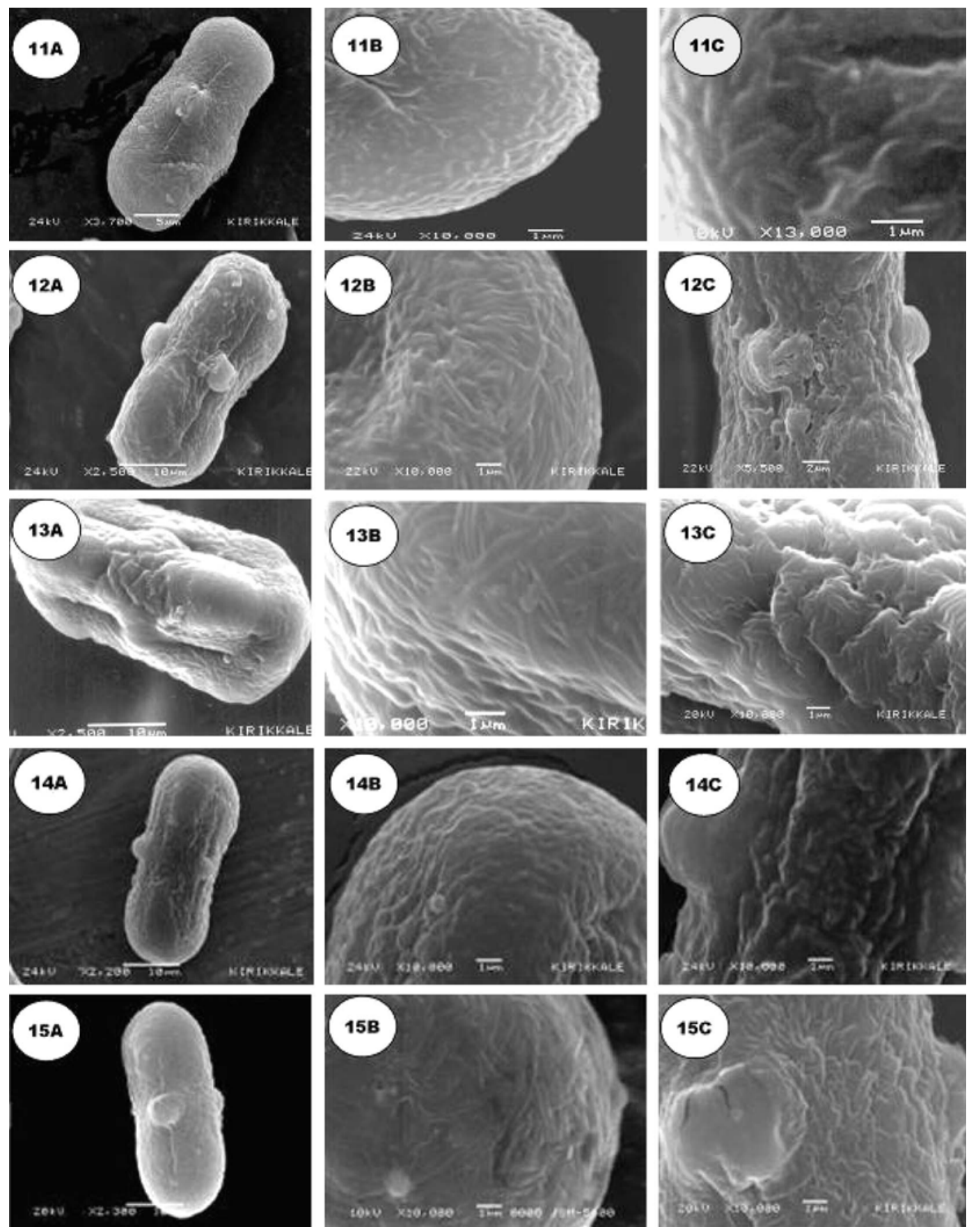

Figs 11-15. SEM microphotographs of pollen grains of Ekimia and Prangos taxa. A, general view; B-C, exine ornamentations. 11. E. bornmuelleri; 12. P. denticulata; 13. P. ferulacea; 14. P. heyniae; 15. P. meliocarpoides. 

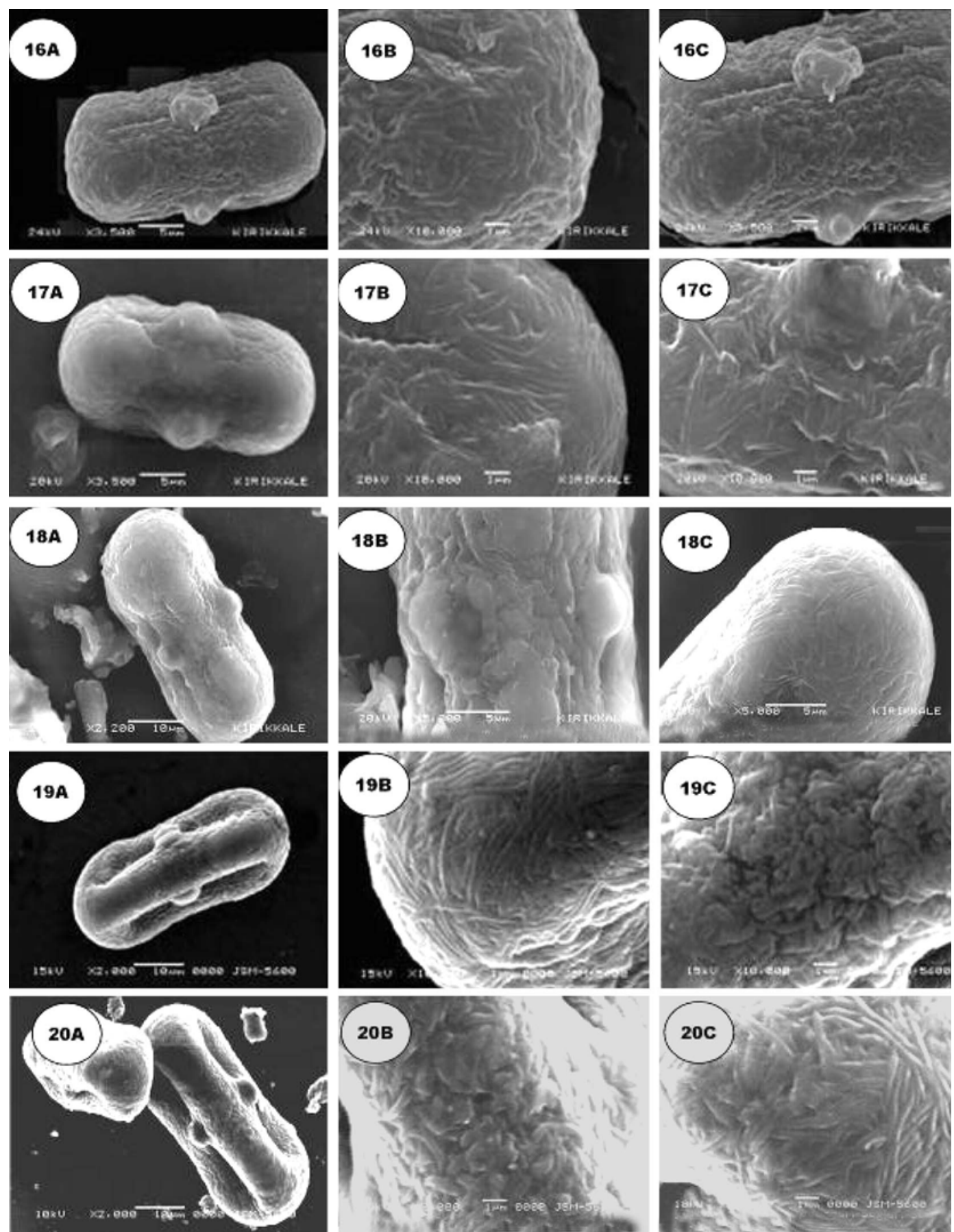

Figs 16-20. SEM microphotographs of pollen grains of Prangos taxa. A, general view; B-C, exine ornamentations. 16. P. pabularia; 17. P. peucedanifolia; 18. P. platychloena subsp. platychloena; 19. P. platychloena subsp. engizekensis; 20. P. uechtrizii. 


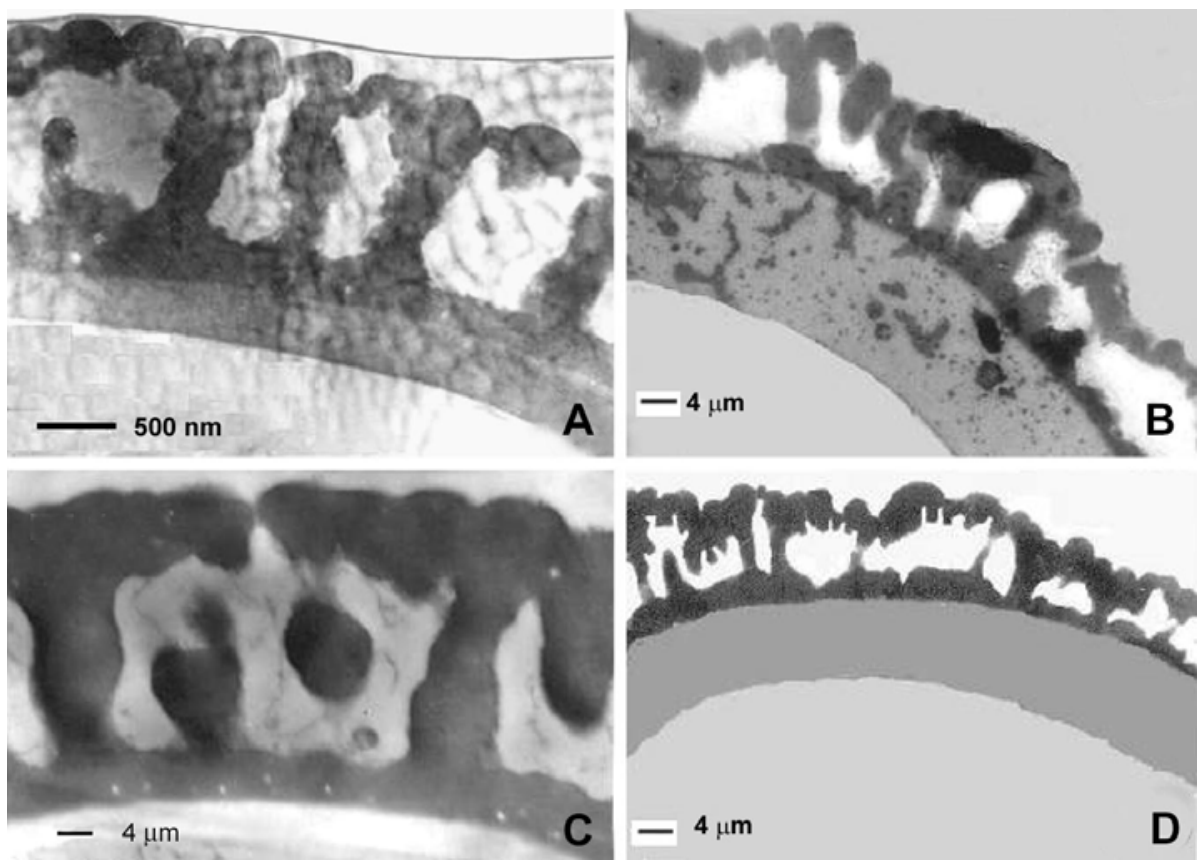

Fig. 21. TEM microphotographs of exine structure of pollen grains of Ekimia and Prangos taxa. A. E. bornmuelleri; B. P. heynia; C. P. meliocarpoides; D. P. pabularia.

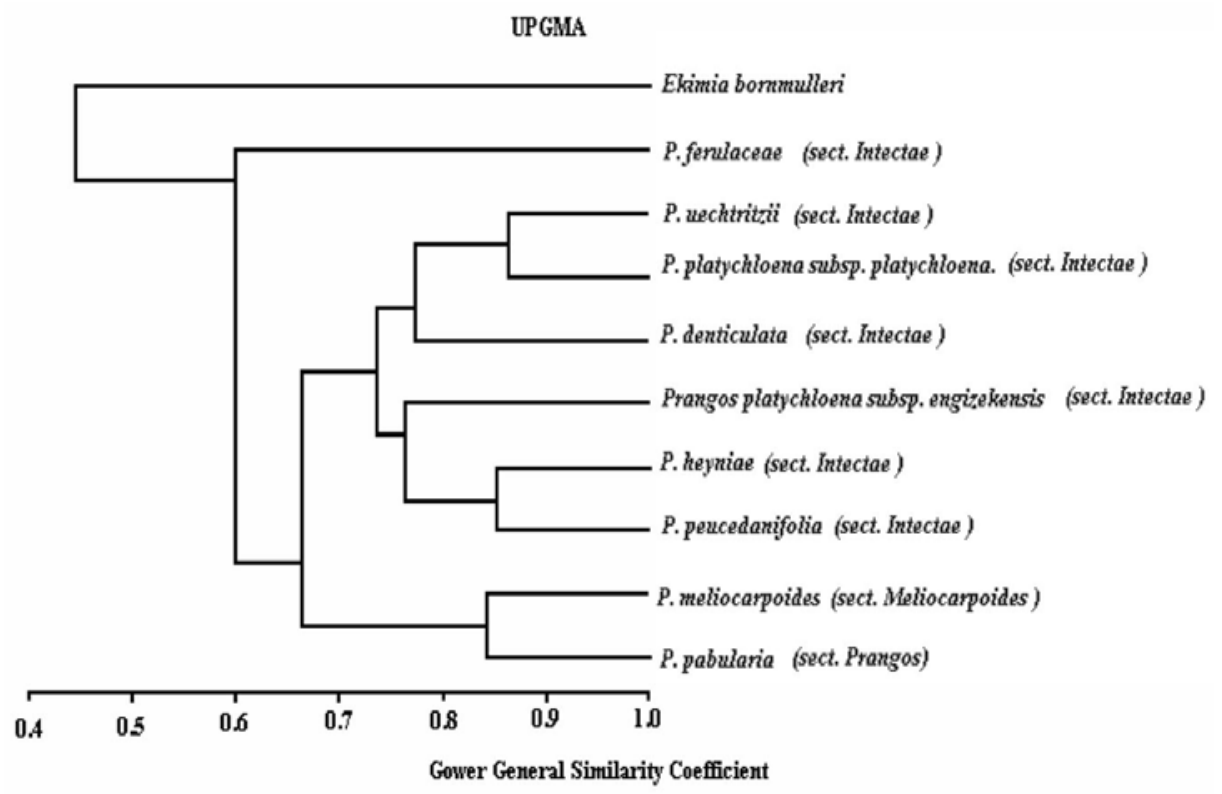

Fig. 22. UPGMA phenogram of the investigated Ekimia and Prangos taxa based on Gower General Similarity Coefficient. 
Table 3. Transmission electron microscope (TEM) characteristics of four taxa of Ekimia and Prangos.

\begin{tabular}{lcccc}
\hline Taxon & \multicolumn{3}{c}{ Ectexine $(\mu \mathrm{m})$} & Endexine $(\mu \mathrm{m})$ \\
\cline { 2 - 4 } & Tectum & Columella & Food layer & \\
\hline E. bornmuelleri & 0.28 & 0.75 & 0.30 & 0.33 \\
P. heyniae & 0.23 & 0.80 & 0.38 & 0.55 \\
P. meliocarpoides & 0.25 & 0.50 & 0.27 & 0.46 \\
P. pabularia & 0.35 & 1.05 & 0.40 & 0.48 \\
\hline
\end{tabular}

The obtained UPGMA phenogram (Fig. 22) based on Gower General Similarity Index supplements that the genus Ekimia (E. bornmuelleri) is distinctly different from the members of the Prangos concerning the quantitative pollen data. Section Intactae members form a cluster except $P$. ferulacea taxa.

The application of statistical methods, in this study the cluster analysis, proved the viability of using quantitative pollen data as taxonomic characters for effective discrimination, especially among genera.

\section{Acknowledgements}

The authors thank to the curators of four herbaria, namely ANK (Ankara University), FUH (Frrat University), GAZI (Gazi University) and HUB (Hacettepe University), who allowed formers to study their Prangos specimens; Yrd. Doç. Dr. Hakan Güngüneş who helped in taking electron photographs of pollen surface; and Prof. Hayri Duman for providing some samples. The authors also appreciate the valuable efforts of Dr. Hülya Özler and Mr. Umut Toprak for editing an early version of the manuscript. This study was supported by Gazi University under grant 05/2001-37.

\section{References}

Aytuğ, E., Aykut, N.M. and G. Edis, 1971. Atlas de Pollens des environs d'Istanbul. Kutulmuş Press, Istanbul, pp. 1-328. (in French)

Cerceau-Larrival, M.Th. and Roland Heydacker, F. 1976. The evolutionary significance of the ultrastructure of the exine in Umbelliferous pollen grains. In: Ferguson, I.K. and Muller, J. (eds), The Evolutionary Significance of the Exine. Linn. Soc. Symp., Ser. 1: 481-498.

Cerceau-Larrival, M.Th. 1962. Le Pollen D'Ombelliferes Mediterraneennes. I. Echinophoreae. Pollen \& Spores 5: 95-104. (in French)

Cerceau-Larrival, M.Th. 1963. Le Pollen D'Ombelliferes Mediterraneennes.II. Tordylinae. Pollen \& Spores 5: 297-323. (in French)

Cerceau-Larrival, M.Th. 1965. Le Pollen D'Ombelliferes Mediterraneennes. III. Scandicineae. Pollen \& Spores 7: 35-62. (in French) 
Cerceau-Larrival, M.Th. 1971. Morphologie Pollinique et Correlations Phylogenetiques Chez Les Ombelliferes. In: Heywood, V.H. (ed.), The Biology of Chemistry of the Umbelliferae. J. Linn. Soc., Suppl., pp. 109-156. (in French)

Davis, P.H., Mill, R.R. and Tan, K. 1988. Prangos Lindl. In: Davis, P.H., Mill, R.R. and Tan, K. (eds), Flora of Turkey and East Aegean Islands (Suppl. 1) 10: 151. Edinburgh Univ. Press, Edinburgh.

Duman, H. 2000. Prangos Lindl. In: Güner, A., Özhatay, N., Ekim, T. and Başer, K.H.C. (eds.), Flora of Turkey and the East Aegean Islands (Suppl. 2) 11: 141-142. Edinburgh Univ. Press, Edinburgh.

Duman, H. and Watson, M.F. 1999. Ekimia, A new genus of Umbelliferae and two new taxa of Prangos Lindl. (Umbelliferae) from southern Turkey. Edinburgh J. Bot. 56(2): 199-201.

Duran, A., Sağıroğlu, M. and Duman, H. 2005. Prangos turcica (Apiaceae), a new species from South Anatolia, Turkey Ann. Bot. Fennici 42: 67-72.

Erdtman, G. (ed.) 1952. Pollen Morphology and Plant Taxonomy, Angiosperms. The Chronica Botanica Co., Walthan, Mass., Almquist Wiksell, Stockholm, Sweden, pp. 1-539.

Erdtman, G. 1960. The Acetolysis Method. A revised description. Svensk Bot. Tidskr. 54: 561-564.

Faegri, K. and Iversen, J. (eds) 1989. Textbook of Pollen Analysis. John Wiley and Sons, New York, pp. 1328.

Ferreira, A.G. and Purper, C. 1972. Pollen grains of Umbelliferae from Rio Grande do Sul. III. Rev. Bras. Biol. 32: 15-19.

Gower, J.C. 1971. A general coefficient of similarity and some of its properties. Biometrics 27: 857-871.

Herrnstadt, I. and Heyn, C.C. 1972. Prangos Lindl. In: Davis, P.H. (ed.), Flora of Turkey and the East Aegean Islands. Vol. 4. University Press, Edinburgh, Scotland, pp. 382-388.

Herrnstadt, I. and Heyn, C.C. 1977. A monographic study of genus Prangos (Umbelliferae) Boissiera 26, Mémoires du Conservatoire de Botanique et de l'Institut de Botanique Systematique de l'Universite de Geneve. Geneva, pp. 1-91.

Kovach, W.L. 1999. MVSP - a multivariate statistical package for windows. Version 3.1. Pentraeth: Kovach Computing Services.

Moore, P.D., and Webb, J.A. (eds) 1978. An Illustrated Guide to Pollen Analysis. Hodder and Stoughton, London. pp. 1-133.

Punt, W. 1984. The Northwest European pollen flora IV. Rev. Paleobot. Palyn. 42: 155-369.

Reynold, E.S. 1963. The use of lead citrate at high $\mathrm{pH}$ as on electron opaquestain in electron microscope. Stain Technol. 43: 139-144.

Skvarla, J.J. and Turner, B.L. 1966. Systematic implications from electron microscopic studies of Compositae - a review. Annals of the Missouri Botanical Garden 53: 220-256.

Wodehouse, R.P. 1935. Pollen Grains. Hafner, New York, pp. 1-435.

(Manuscript received on 8 January 2009; revised on 15 July 2009) 